\title{
THE MECHANICAL BEHAVIOR OF FIBER REINFORCED HIGH PERFORMANCE SELF COMPACTED CONCRETE AT HIGH TEMPERATURES
}

\author{
A. A. M. Badawy ${ }^{1}$, M. H. Seleem ${ }^{1}$, A. M. El shihy ${ }^{2}$ and A. E. K. Gabal ${ }^{1}$ \\ ${ }^{1}$ Materials Engineering Dept., Faculty of Engineering, Zagazig, Egypt \\ ${ }^{2}$ Structural Engineering Dept., Faculty of Engineering, Zagazig, Egypt
}

\begin{abstract}
In this paper, an experimental work was carried out to study the effect of high temperatures on the strength of high-performance self compacting concrete (HPSCC). Four concrete mixes were investigated. The first mix represented HPSCC without fibers. The second mix represented HPSCC including steel fibers. The third mix represented HPSCC including steel and micropolypropylene fibers. The fourth mix represented HPSCC including steel, polypropylene and polyolefin fibers. Compressive, tensile and flexural strengths were measured at room temperature (RT) and after exposure to high temperatures of $200^{\circ} \mathrm{C}, 400^{\circ} \mathrm{C}, 600^{\circ} \mathrm{C}$ and $750^{\circ} \mathrm{C}$ for 2 hours. The residual unstressed test method was followed. Microscopic examination was performed on concrete samples from the four mixes at RT and after exposure to high temperatures. The results showed that incorporating hybrid fibers seems to be a promising way to enhance the resistance of HPSCC to thermally induced explosive spalling and increase the residual strengths.

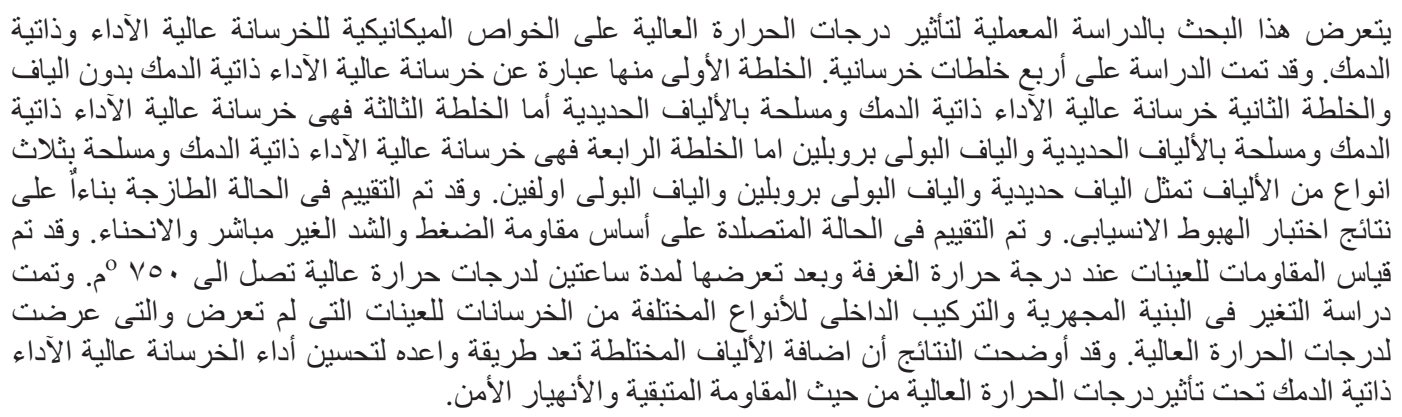

Keywords: High-performance concrete; Self compacted concrete; Residual strengths; Hybrid Fibers; High temperatures.

\section{INTRODUCTION}

The addition of pozzolanic or supplementary cementing materials as partial replacements is one effective method of preparing high-performance concrete (HPC). These blending materials enhance the performance of concrete through pozzolanic reaction and filling effect. Recently, self compacted concrete (SCC) has gained wide use in many countries for different applications and structural configurations. The use of SCC is a valuable solution to accelerate the placement rate and reduce labor demand needed for vibration and surface finishing of the construction of basement and foundation walls in residential structures that present limited restriction to spreading fresh concrete [1].
Fire represents one of the most severe risks to buildings and structures. Many studies investigated the properties of ordinary concrete exposed to high temperature. Fewer studies have been carried out with HPC than with ordinary concrete [2]. While the strength, workability and durability of HPC are usually greatly superior to those of conventional concrete at ambient temperature, their failure is sometimes rapid and dramatic when exposed to fire, characterized by explosive spalling [3]. Experimental studies showed that fire resistance of concrete is affected by many factors like the type of aggregate and cement used and its composition, the duration of the fire, size of structure members and moisture content of concrete [4]. Although the failure mechanisms of HPC spalling have not been sufficiently understood, there are two mechanisms, which are considered as the direct causes of spalling 
of HPC. One is the thermal stress induced by the rapid temperature rise or thermal shock; the other is the water vapor, which may cause high pore vapor pressure [5-7]. Other investigations [8, 9] found that moisture content and strength level of concrete are two main factors governing thermally induced explosive spalling. If the strength of concrete is below a certain value, $60 \mathrm{MPa}$, no spalling will occur, even at a high moisture content level. When the concrete strength exceeds that strength value, the higher the moisture content the greater the spalling probability. Due to the potentially poor fire resistance of HPC, it might be recommended that the use of HPC should be limited in some cases unless future research is carried out to study and solve this problem. Fibers have extensively been used to improve the ductility of concrete [10-14]. Recently, it has been found that a number of fibers can also improve the residual properties of concrete after exposure to elevated temperatures [15-17]. Although, polypropylene (PP) fibers and steel fibers (SF) have been used to reduce spalling and cracking and to enhance the residual strength [18, 19], minimal or even negative effects of PP fibers on the residual performance of the heated concrete were observed $[20,21]$. Topics on this issue are still open for investigation. Therefore, detailed investigation regarding high temperature performance of HPC is required worldwide. For this reason, the objective of this investigation is to increase the understanding of residual strengths (compressive, splitting tensile and flexure) of HPSCC prepared with and without fibers after exposure to high temperatures ranging from RT to $750{ }^{\circ} \mathrm{C}$ for 2 hours.

\section{MATERIALS AND METHODS}

The materials used in this study were Type I ordinary Portland cement, quartz fine sand having maximum nominal size of $0.6 \mathrm{~mm}$ and specific gravity of 2.75, superplasticizer based on modified polycarboxylic ethers polymer technology and silica fume. In the case of portland cement, 18\% silica fume (in cement weight) is theoretically enough for the total consumption of calcium hydroxide released from cement. Concerning the filling effect, more than $25 \%$ silica fume should be added to concrete to get the densest granular mixture producing HPSCC $[22,23]$. Silica flour having a specific gravity of 2.21 and a diameter ranging from 0.125 to $1.0 \mathrm{~mm}$ was used as micro filler to optimize the packing density of the powder mixture. Steel fibers filaments of high strength wire with $0.2 \mathrm{~mm}$ diameter, Dramix, were used, while two types of polypropylene (PP) fibers were used. The first type was micro-PP, rheofiber $12 / 18$. The second type was the Polyolefin (PO) fibers 25/38 from 3M Company UAE. Typical physical properties of the used fibers are given in Table 1.
The experimental program was performed on four concrete mixes representing different types of HPSCC with different types of fibers. The first mix (Mix I) represented HPSCC made without fibers. The second mix (Mix II) represented HPC made with $1.3 \%$ SF. The third mix (Mix III) represented HPSCC made with $1.3 \%$ SF, and $0.13 \%$ PP fibers. The fourth mix (Mix IV) represented HPSCC made with $1.3 \% \mathrm{SF}$, and $0.13 \% \mathrm{PP}$ in the addition to $0.6 \%$ PO fibers. Designed concrete mix of HPSCC is optimized to reach good flow-ability and sufficient workability time, in parallel with the needed mechanical properties of a hardened mass. All fibers were added as a ratio by volume of the whole batch. The mix proportions are given in Table 2.

The mixing procedures can be summarized as follows: Weight all constituent materials. Dry mixing of sand and silica fume was in less than $1.5 \mathrm{~min}$. Adding $50 \%$ of water to wetting the surface of the materials within $1.5 \mathrm{~min}$ in order to avoid agglomeration of the silica fume. Adding cement and quartz powder for $1 \mathrm{~min}$. Adding super-plasticizer through the remaining amount of water by about 5 minutes after the first contact between water and cement to enhance the effectiveness of the superplasticizer and produce better setting behavior. Finally, adding fibers through sieve slowly for 2 min. After the addition of fibers, continue running mixer for 4 minutes to ensure that the fibers are well dispersed. After the completion of mixing the fresh properties of the mixed materials were measured based on the slump flow test and the results are given in Table 3.

One hundred and eighty specimens were cast for the residual unstressed test (RUST). One hundred and twenty from which were cylindrical specimens of $100 \mathrm{~mm}$ diameter and $200 \mathrm{~mm}$ height for compression and indirect tension tests. The remaining sixty specimens were beams of $100 \times 100 \times 350 \mathrm{~mm}$ dimensions for the flexure test. After de-molding, one day after casting, the specimens were immersed in curing water at $23 \pm 2{ }^{\circ} \mathrm{C}$ for 28-days. The specimens were heated in an electric furnace to temperatures of $200,400,600$ and $750{ }^{\circ} \mathrm{C}$, at a heating rate of about $10{ }^{\circ} \mathrm{C} / \mathrm{min}$.

When the target temperature (TT) was reached, the temperature was maintained for 2 hrs and then the specimens were naturally cooled at RT. After that, the specimens were tested under compression, indirect tensile or flexural loading for the estimation of the residual mechanical strengths. Samples from all mixes tested at RT or after exposure to high temperatures were prepared and examined using light microscope (Digital USB Microscope, Trace Porta-Scope 1.3mp 10X - 200X) and Scanning Electron Microscopy (SEM) to demonstrate the change in concrete microstructure. 
A. A. M. Badawy, M. H. Seleem, A. M. El shihy, A. E. K. Gabal, "The Mechanical Behavior of Fiber ..."

Table 1, Typical physical properties of the used fibers

\begin{tabular}{||l|c|c|c||}
\hline \multirow{2}{*}{\multicolumn{1}{|c|}{ Properties }} & \multicolumn{2}{c||}{ Polypropylene Fibers (PP) } & \multirow{2}{*}{ Steel Fiber } \\
\cline { 2 - 4 } & Polyolefin & Micro- Polypropylene & \\
\hline Fiber Length (mm) & 25 & 12 & 13 \\
\hline Fiber Diameter (mm) & 0.38 & 0.018 & 0.20 \\
\hline Aspect Ratio & 65.8 & 666.7 & 65 \\
\hline Specific Gravity & 0.91 & 0.91 & 7.85 \\
\hline Tensile Strength $(\mathrm{MPa})$ & 275 & $320-400$ & 2000 \\
\hline Modulus of Elasticity $(\mathrm{GPa})$ & 2.65 & $3.5-3.9$ & 1500 \\
\hline Melting Point $\left({ }^{\circ} \mathrm{C}\right)$ & 160 & 160 & \\
\hline
\end{tabular}

Table 2, Materials required to produce one cubic meter from the different mixes

\begin{tabular}{|c|c|c|c|c|c|c|}
\hline \multirow{2}{*}{\multicolumn{3}{|c|}{ Materials }} & \multicolumn{4}{|c|}{ Mixes Proportions } \\
\hline & & & Mix I & Mix II & Mix III & Mix IV \\
\hline \multicolumn{3}{|l|}{ Cement (kg) } & 700 & 700 & 700 & 700 \\
\hline \multicolumn{3}{|c|}{ Silica Fume (kg) } & 203 & 203 & 203 & 203 \\
\hline \multicolumn{3}{|l|}{ Sand (kg) } & 1080 & 1080 & 1080 & 1080 \\
\hline \multirow{2}{*}{\multicolumn{2}{|c|}{ Silica Flour (kg) }} & $20 \mu \mathrm{m}$ & 90 & 90 & 90 & 90 \\
\hline & & $75 \mu \mathrm{m}$ & 90 & 90 & 90 & 90 \\
\hline \multicolumn{3}{|c|}{ Super Plasticizer (lit) } & 38 & 38 & 38 & 38 \\
\hline \multicolumn{3}{|l|}{ Water (lit) } & 161 & 161 & 161 & 161 \\
\hline \multicolumn{3}{|c|}{ Steel Fiber ( Dramix) } & - & $1.30 \%$ & $1.30 \%$ & $1.30 \%$ \\
\hline \multirow{2}{*}{ polypropylene } & & & - & - & $0.13 \%$ & $0.13 \%$ \\
\hline & & & - & - & - & $0.60 \%$ \\
\hline \multicolumn{3}{|c|}{ Silica fume/Cement (s/c) } & \multicolumn{4}{|c|}{$29.0 \%$} \\
\hline \multicolumn{3}{|c|}{ Water/Cement (w/c) } & \multicolumn{4}{|c|}{0.23} \\
\hline \multicolumn{3}{|l|}{ W/Binder } & \multicolumn{4}{|c|}{$18.0 \%$} \\
\hline
\end{tabular}

Table 3, Slump flow values for the HPSCC mixes

\begin{tabular}{|l|c|c|}
\hline \multicolumn{1}{|c|}{ Mix } & Slump flow diameter, $\mathbf{~ m m}$ & $\mathbf{T}_{\mathbf{5 0}}$, sec \\
\hline Mix I & 770 & 3.9 \\
\hline Mix II & 750 & 4.1 \\
\hline Mix III & 720 & 4.3 \\
\hline Mix IV & 710 & 4.5 \\
\hline
\end{tabular}

Table 4, Mechanical strengths of HPSCC at RT

\begin{tabular}{||l|c|c|c|c||}
\hline \hline Mechanical Strengths & Mix I & Mix II & Mix III & Mix IV \\
\hline Compressive Strength, MPa & 132.36 & 130.80 & 129.82 & 119.64 \\
\hline Tensile Strength, MPa & 10.02 & 10.75 & 10.98 & 12.05 \\
\hline Flexural Strength, MPa & 12.90 & 16.30 & 16.75 & 17.03 \\
\hline
\end{tabular}




\section{RESULTS AND DISCUSSION}

The results of the mechanical strengths (compressive, tensile and flexure) measured at room temperature (RT) for the four investigated mixes are given in Table 4.

\subsection{Behavior at High Temperatures}

The results of the residual compressive, tensile and flexural strengths, for the four concrete mixes, after exposure to high temperatures ranging from 200 to $750{ }^{\circ} \mathrm{C}$ are plotted in Figs. 1 to 3, respectively. The residual strengths in the figures represent the normalization of the strength measured after exposure to high temperature to that of the unheated specimens of the corresponding mix. Each point represents the average of three specimens.

The three figures clearly demonstrate that the behavior can be divided into two ranges, namely 25$200{ }^{\circ} \mathrm{C}$ and $200-750{ }^{\circ} \mathrm{C}$. In the range $25-200{ }^{\circ} \mathrm{C}$, the strengths slightly increase for some mixes or decrease for other mixes. The fiber concrete show a slight increase in the residual strengths, while a slight decrease was observed for concrete without fibers, Mix (I). The enhancement in the residual strengths of fibered concrete can be attributed to the generation of an internal steam pressure inside concrete as a result of the continuity of water evaporation from concrete pores, which forced the hydration process and leads to an enhancement in the mechanical strengths. The decrease in the strength of plain concrete, Mix (I), may be due to the formation micro-cracks as a result of steam pressure generation inside the condense concrete. This eliminates the enhancement in the strength due to the hydration process.

In the range $200-750{ }^{\circ} \mathrm{C}$, these concretes lost most of their original strength, where the strengths are markedly decreased to loss approximately $85 \%$ of its original RT strengths at $750^{\circ} \mathrm{C}$ for all mixes. Thus the range $200-750{ }^{\circ} \mathrm{C}$ may be regarded as a critical temperature range for the strength loss of fiber concretes, which is similar to that found for concrete without fibers [6].

The reduction in concrete strength may be attributed to several reasons: 1) Physical forces such as steam pore pressure. The steam pressure produces stress, which the material is unable to resist. 2) Chemical stresses, where high temperatures increase dehydration and cause decomposition of hardened cement paste and aggregates, such as an inversion of quartz at $573^{\circ} \mathrm{C}$ from $\alpha$-phase to the $\beta$-phase for siliceous and calcareous quartz sand, and a dissociation of $\mathrm{Ca}(\mathrm{OH})_{2}$ between $450^{\circ} \mathrm{C}$ and $500^{\circ} \mathrm{C}$ in addition to oxidization of steel fibers. All of these micro changes degenerate the macro-properties that cause strength to decrease and damage to increase, and 3) Thermal stresses: due to the differential thermal expansion between concrete matrix components itself and between concrete matrix and fibers [15].

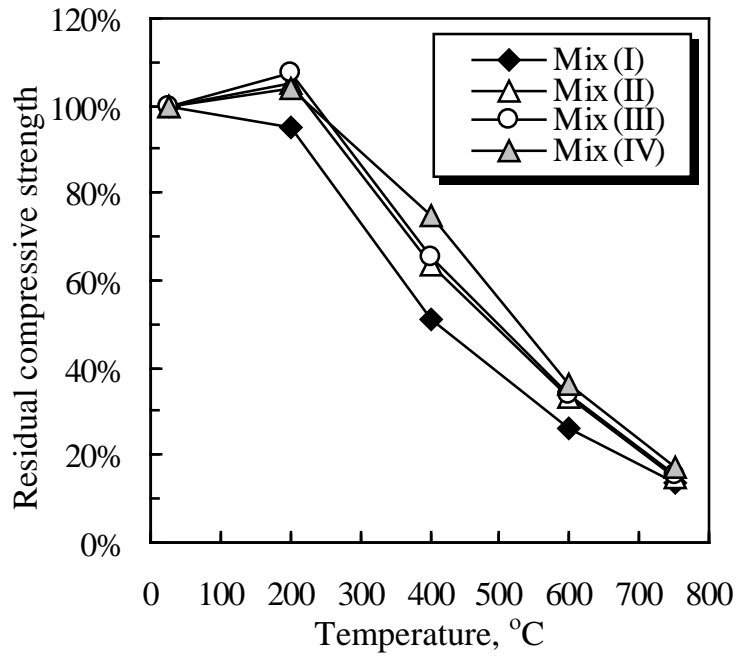

Fig. 1 Effect of high temperatures on the residual compressive strength

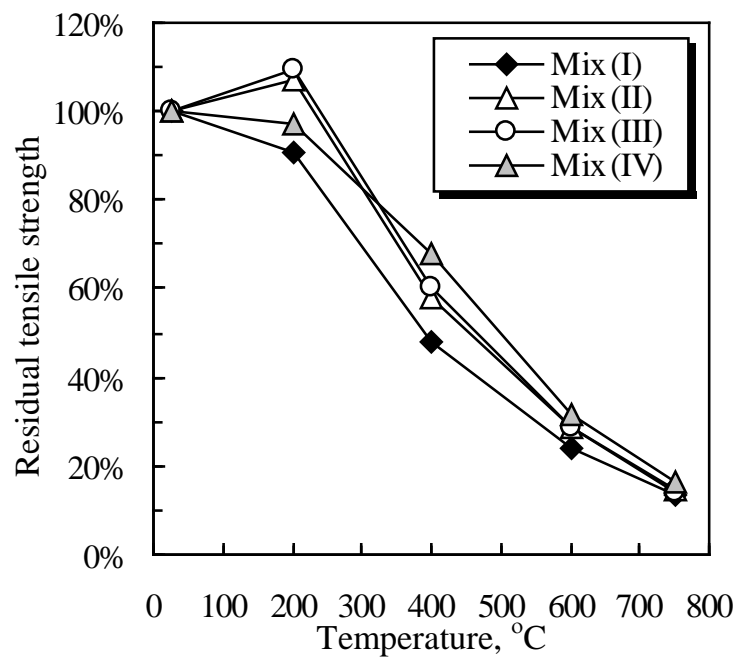

Fig. 2 Effect of high temperatures on the residual tensile strength

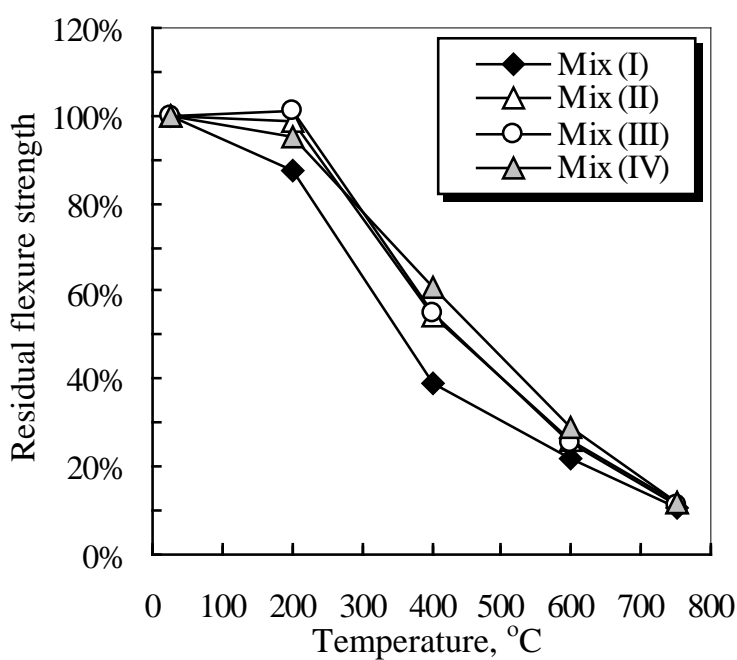

Fig. 3 Effect of high temperatures on the residual flexure strength 


\subsection{Effect of Fibers Addition}

To demonstrate the effect of fibers addition either single, Mix (II) or hybrid, Mix (III) and Mix (IV) on the mechanical strengths at RT or after exposure to high temperatures, the relative strengths were estimated. This relative strength is the ratio of strength of HPSCC mix with fibers to that without fibers at the same temperature. The results of the relative strengths for the investigated mixes at different exposure temperatures are shown in Fig. 4.

\subsection{Effect of fiber addition at RT}

The results of the relative strengths at RT illustrated in Table 4 show that, adding fibers to HPSCC has a slight adverse effect on the compressive strength. The compressive strength decreased marginally with the single type of SF, Mix (II), or two types of SF and micro-PP fibers, Mix (III). A decrease by about $9 \%$ was recorded with the use of the three types of fibers SF, micro-PP and PO; i.e. Mix (IV). The results show an increase in the relative tensile strength with the addition of SF by 7 $\%$, Mix (II), while an increase by an average of $10 \%$ was recorded on using hybrid fibers, Mix (III) and by $20 \%$ when using three types of fibers, Mix (IV). This may be due to the ability of micro-PP fibers to reduce the occurrence of fine cracks in the concrete matrix. On the other hand, a pronounced effect of adding fibers to the HPSCC on the relative flexural strength was recorded. By using SF, Mix (II), the flexural strength increased by about $26 \%$, and by about $30 \%$, when using hybrid fibers from SF and micro-PP, Mix (III), while it increased by about 32\% with the use of three types of fibers, steel, polypropylene and polyolefin, Mix (IV).

\subsection{Effect of fiber addition at $200{ }^{\circ} \mathrm{C}$}

Figure 4 illustrates that, the three mechanical strengths increase with the addition of fibers single type of fibers, Mix II, or two types of fibers, Mix III. The utilization of three types of fibers, Mix IV, cause a slight reduction in the relative compressive strength, while the relative tensile and flexural strengths increased. The increase in the relative tensile or flexural strengths for Mix IV is less than that for Mix III but grater than that for Mix II. Steel fibers may be beneficial to help concrete overcome vapor pressure build-up under high temperatures and hence avoid occurrence of spalling. Melting of PP fibers, as shown in Fig. 5, cause a reduction in the compressive strength. This means that, adding fibers to HPSCC at low temperature (until $200{ }^{\circ} \mathrm{C}$ ) plays a limited role in enhancing the compressive strength while, offers more improvement for tensile and flexural strengths.

\subsection{Effect of fiber addition at $400^{\circ} \mathrm{C}$}

All relative strengths show similar behavior at $400^{\circ} \mathrm{C}$, as shown in Fig.4. By adding fibers all strengths are increase with more pronounced enhancement in both tensile and flexural strengths.
Adding SF, Mix (II), improves the relative strength by $124 \%, 129 \%$ and $178 \%$ for compressive, tensile and flexural strengths respectively. The improvement in the mechanical strengths at this temperature level comes from the ability of SF to have enough bonds with concrete matrix causing strengths enhancement and delay spalling. A slight improvement was observed by adding micro-PP, Mix (III). Adding PO, Mix (IV), reaches by the relative mechanical strengths to the peak to become $133 \%, 171 \%$ and 208\% for compressive, tensile and flexural strengths receptively. Using SF and two types of PP fibers together can provide several benefits by reducing the adverse effect of high temperature on the strengths. The easily melting and dissolving of the PP (at approximate $160^{\circ} \mathrm{C}$ ), then vaporized (at approximate $400^{\circ} \mathrm{C}$ ), creates pores and small channels in the concrete as shown in Fig. 6. This allows moisture and steam transportation with the relaxation of the internal pressures in the heated matrix and thus eliminating the occurrence of spalling, accordingly improving the mechanical strengths especially flexural. In general, up to $400^{\circ} \mathrm{C}$, using hybrid fibers can be not only eliminated spalling, but also mechanical properties can be improved effectively.

\subsection{Effect of Fiber Addition at 600 C}

With the arrival of temperature to $600^{\circ} \mathrm{C}$ dramatically fall in plain concrete mechanical strengths without fibers is observed. At this high temperature still fibers have the ability to mitigate the sever effect of temperature. Adding of SF, Mix (II), or steel and micro-PP fibers, Mix (III), give approximately similar improvement in strengths, while adding PO, Mix (IV) gives the highest enhancement where the strengths become $124 \%$, $159 \%$ and $176 \%$ compressive, tensile and flexural strengths respectively, see Fig. 4. When the cement have been completely dehydrated, at approximate $500^{\circ} \mathrm{C}$, and the PP fibers vaporized, the use of SF still unaltered up to $500^{\circ} \mathrm{C}$. Therefore, the SF contribute to increase the fire resistance of HPSCC and maintain the cohesion of the dehydrated cement. At temperatures above $500^{\circ} \mathrm{C}$, the SF oxidized become brittle and contribute to the development of cracks. After exposure to $600^{\circ} \mathrm{C}$, the strengths decreased drastically. The reason is due to not only the deterioration of the properties of concrete itself, but also the degradation of physical and mechanical properties of SF. Steel fibers react with oxygen and

water to produce various iron oxides at high temperatures, as shown in Fig. 7. Also, we should not forget the volumetric expansion problems occurring at $573^{\circ} \mathrm{C}$ due to the change of crystal phases from $\alpha-$ phase to the $\beta$-phase for siliceous and calcareous quartz sand as a reason of spalling.

\subsection{Effect of Fiber Addition at $750^{\circ} \mathrm{C}$}

Referring to Fig. 4, a significant improvement in the relative strengths with the addition of fibers can 
be observed for all strengths. This improvement is less than that recorded at $600^{\circ} \mathrm{C}$. This is due to the totally changes in physical and chemical properties of concrete constituents (aggregate, bonding materials and fibers). At $750^{\circ} \mathrm{C}$, the addition of SF improves the compressive, tensile and flexural strengths by

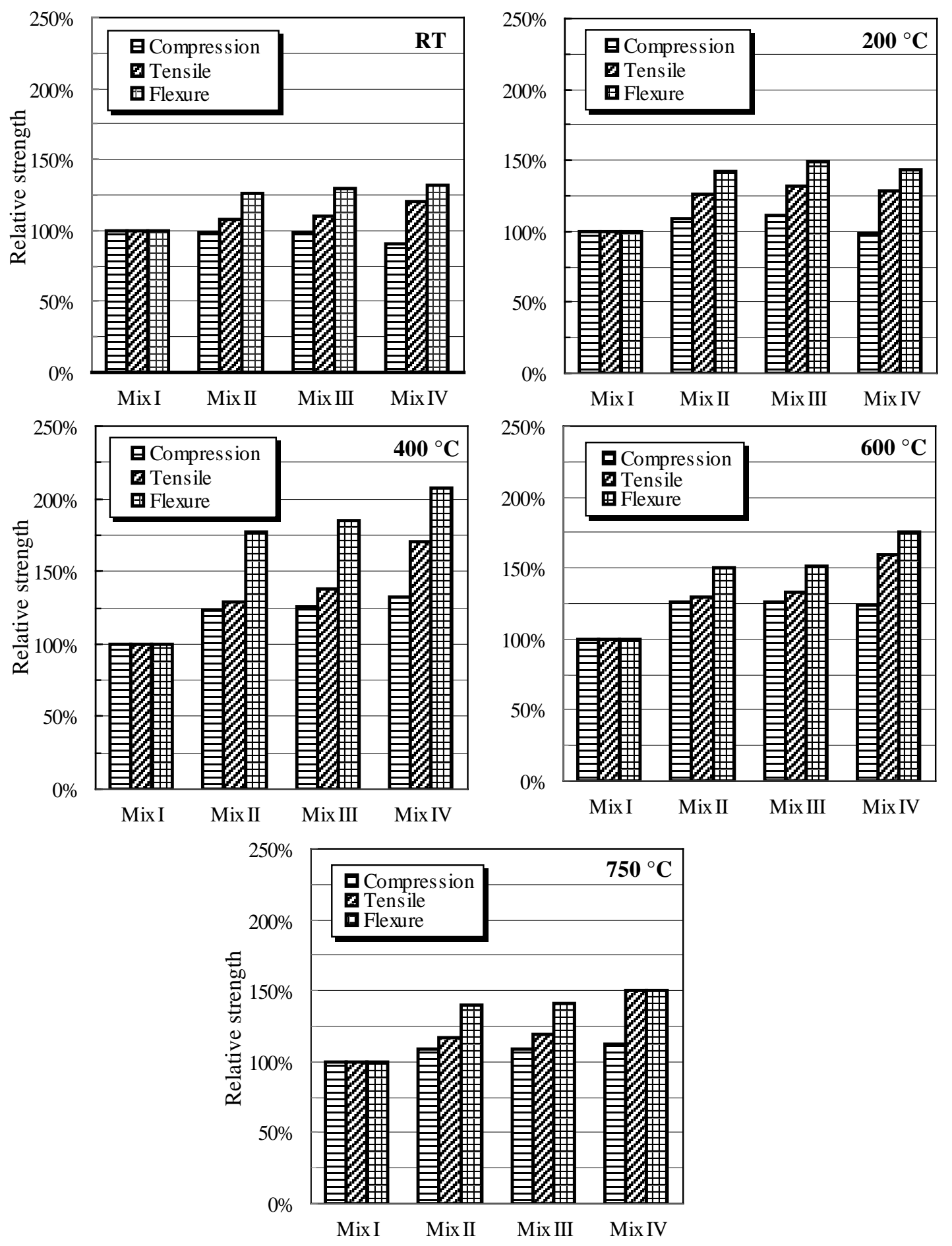

Fig. 4 Relative strengths for different mixes at different exposure temperatures about $108 \%, 117 \%, 140 \%$ respectively. Adding steel and micro-PP fibers, Mix (III), give approximately the same improvement, Mix (II). On the other hand, adding PO, Mix (IV), enhances the relative strengths to become $112 \%, 150 \%$ and $150 \%$ respectively, as shown in Fig. 4. 

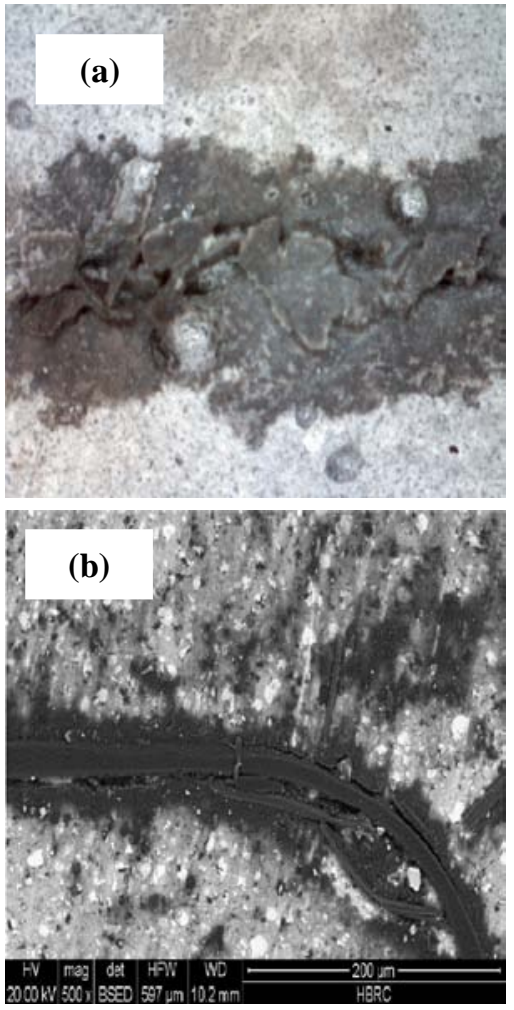

Fig. 5 Melted polypropylene at (a) specimen surface and (b) inside the specimen at $200^{\circ} \mathrm{C}$

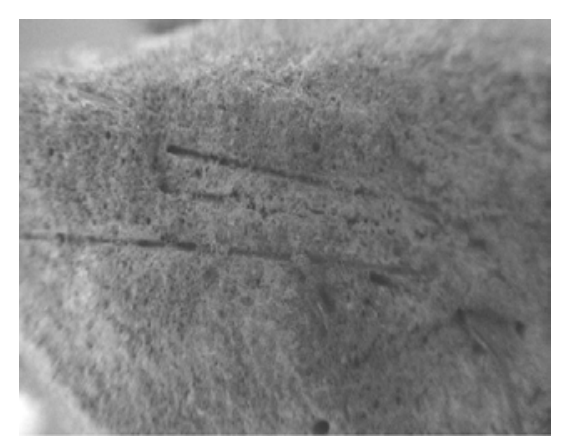

Fig. 6 The beds of melted PP fibers at $400^{\circ} \mathrm{C}$

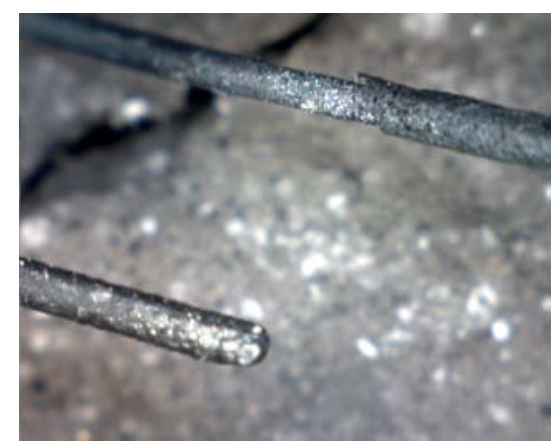

Fig. 7 Oxidation of SF at $600{ }^{\circ} \mathrm{C}$

\subsection{Failure Mode of HPSCC}

Visual inspections of concrete specimens were occurred. It is found that:

1-Networks of micro-cracks were observed on plain concrete specimens (without fibers) heated to a maximum temperature of $200{ }^{\circ} \mathrm{C}$. With further increases in maximum temperatures exceeding $400{ }^{\circ} \mathrm{C}$, a considerable number of micro-cracks were found becoming deeper at temperature of $600{ }^{\circ} \mathrm{C}$. For maximum temperatures beyond 600 ${ }^{\circ} \mathrm{C}$, severe cracking occurs on concrete specimen surfaces as shown in Fig. 8. For fibered concrete, it is observed that micro-cracks first appeared at about $400{ }^{\circ} \mathrm{C}$ and severe cracking occurs at temperatures exceeding $600{ }^{\circ} \mathrm{C}$. Thus, it is believed that the presence of steel fibres can delay the spread of cracking.

2- Within temperature range of 200-400 ${ }^{\circ} \mathrm{C}$, significant deterioration could not be avoided and explosive spalling is observed in plain concrete, Mix (I). On the other hand, no explosive spalling is observed in the specimen containing fibers. This behavior may be due to use of low melting point fiber (PP) in HPSCC. The melted fibers lead to integrate artificial pores or channels into the high strength concrete matrix, in which the developing water vapor pressure can be relieved to a level similar to normal concrete with sufficient capillary pore. Also the addition SF may be beneficial to help concrete overcome vapor pressure build-up under high temperatures and hence avoid occurrence of spalling and bridging thermal induced cracks and cracks generated during loading. This prevented the sudden drop in the applied load and maintains the residual strength after heating. Therefore incorporating hybrid fibers seems to be a promising way to enhance resistance of concrete to thermally induced explosive spalling and increase the residual strengths, which was experimentally confirmed by this investigation.

3- As temperature increases, the colour of concrete changes. When the temperature was lower than $400{ }^{\circ} \mathrm{C}$, the colour in the center part of the ruptured section was almost the same as on the surface. The colour distribution was non-uniform within cross-sections, when the temperature was beyond $500{ }^{\circ} \mathrm{C}$. Generally speaking, the concrete in the centre within a ruptured section was darker than that on the surface. 


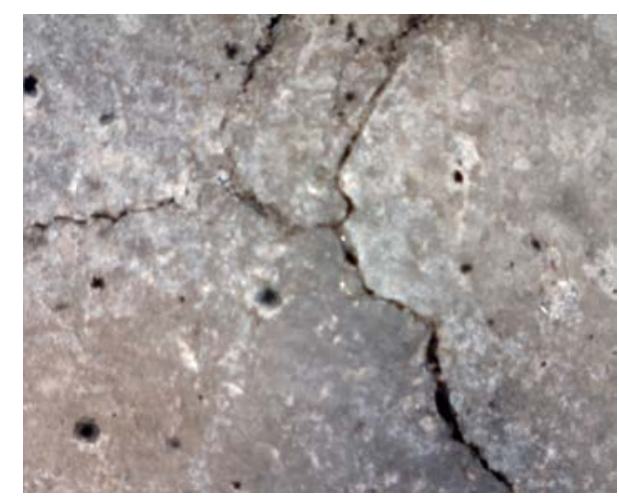

Fig. 8 Severe cracking at $750{ }^{\circ} \mathrm{C}$

\section{CONCLUSIONS}

Based on the results of this experimental work, the following conclusions can be drawn:

1. The HPSCCs with fiber have higher residual strengths than that of concrete without fiber for all temperature range.

2. The concrete strength was reduced sharply after exposure to high temperatures to loss approximately 85-90 \% of its RT strength at $750^{\circ} \mathrm{C}$ for all mixes.

3. Adding fibers to plain concrete at low temperature (until 200C) plays a limited role in influencing the residual compressive strength, while offers more improvement for tensile and flexural strengths.

4. At temperatures above $500^{\circ} \mathrm{C}$, the steel fibers are oxidized, become brittle and contribute to the development of cracks. Therefore, after exposure to $600^{\circ} \mathrm{C}$, the mechanical behavior decreased drastically.

5. The hybrid fiber reinforcement in high strength concrete mix, Mix (IV), gives the highest residual strengths for temperature above $300^{\circ} \mathrm{C}$. Incorporating hybrid fibers seems to be a promising way to enhance resistance of concrete to thermally induced explosive spalling and increase the residual strenghts, which was experimentally confirmed by this investigation.

\section{REFERENCES}

[1] M. H. Seleem, A. A. M. Badawy and H. A. Shehab Eldin, "Effect of Sand Aggregate Ratio and Type of Coarse Aggregate on the Properties of Self Compacting Concrete”, Engineering Research Journal, Faculty of Engineering Minoufiya University, Vol. 29, No. 1, January, pp. 105-112, 2006.

[2] Metin Husem, "The effects of high temperature on compressive and flexural strengths of ordinary and high-performance concrete", Fire Safety Journal, Vol. 41, pp. 155-163, 2006.

[3] Khoury GA. "Effect of fire on concrete and concrete structures", Progress in Structural
Engineering and Materials, Vol.2, No.4, pp. 429-447, 2000.

[4] Phan LT, Lawson JR, Davis FL., "Effects of elevated temperature exposure on heating characteristics, spalling, and residual proportion of high-performance concrete”, Materials and Structures, Vol.34, No.236, pp.83-91, 2001.

[5] Sammy Yin Nin Chana,U, Xin Luob, Wei Sunb, "Effect of high temperature and cooling regimes on the compressive strength and pore properties of high performance concrete”, Construction and Building Materials, Vol. 14, pp.261-266, 2000.

[6] El-Shihy, A. M.; Seleem, M.H.; Shoaib, M.M.; Badawy, A.A. M, and Gabal, A.E. K. "Effect of Elevated Tempreaures on the Mechanical and Physico-Chemical Behavior of Normal, High Strength and Light Weight Concrete", Fourth International Engineering Conference, Mansoura University, Vol. 3, April 20 - 22, pp. 51-59, 2004.

[7] M. H. Seleem, A. M. El-Shihy, A. A. M. Badawy, A. E. K. Gabal“ Concrete Strength Under Different Modes of Thermo-Mechanical Loading Conditions”, Alexandria Engineering Journal, Vol. 46, No. 4, pp. 537-549, 2007.

[8] Gai-Fei Peng, Wen-Wu Yang, Jie Zhao, YeFeng Liu, Song-Hua Bian, Li-Hong Zhao, "Explosive spalling and residual mechanical properties of fiber-toughened high-performance concrete subjected to high temperatures", Cement and Concrete Research, Vol.36, pp. 723-727, 2006.

[9] DitaVorechvska, "Relation between Spalling Behavior and Water Content of Concrete", Building Research Journal, Number 4, Vol. 56, pp. 229-240, 2008.

[10] Fischer, G., and Victor C. Li, "Effect of Fiber Reinforcement on the Response of Structural Members”, Engineering Fracture Mechanics Journal, Vol. 74, pp. 258-272, 2007.

[11] Su-Tae Kang, Yun Lee, Yon-Dong Park, JinKeun Kim, “Tensile Fracture Properties of an Ultra High Performance Fiber Reinforced Concrete (UHPFRC) With Steel Fiber", Composite Structures, Vol. 92, pp. 61-71, 2010.

[12] Vitor M. C. F. Cunha; Joaquim A. O. Barros; and José M. Sena-Cruz, "Pullout Behavior of Steel Fibers in Self-Compacting Concrete”, Journal of Materials in Civil Engineering, ASCE, Vol. 22, No. 1, pp. 1-9, January 2010.

[13] M. Najimi, F.M. Farahani and A.R. Pourkhorshidi, "Effects of Polypropylene Fibers on Physical and Mechanical Properties of Concretes”, The Third International Conference on Concrete and Development, Tehran, I.R. Iran, pp. 1073-1081, 2009. 
[14] Y. Ding, Y. Zhang and A. Thomas, "The Investigation on Strength and Flexural Toughness of Fiber Cocktail Reinforced SelfCompacting High Performance Concrete”, Construction and Building Materials, Vol. 23, pp. 448-452, 2009.

[15] A. Lau and M. Anson, "Effect of High Temperatures on High Performance Steel Fiber Reinforced Concrete”, Cement and Concrete Research, Vol. 36, pp. 1698-1707, 2006.

[16] G. A. Khoury and B. Willoughby, "Polypropylene Fibers in Heated Concrete. Part 1:Molecular Structure and Materials Behavior”, Magazine of Concrete Research, Vol. 60, No. 2, pp. 125-136, March, 2008.

[17] Kazuo Watanabe, Mugume Rodgers Bangi and Takashi Horiguchi , "Effect of Elevated Temperatures on Flexural Behavior of Hybrid Fiber Reinforced High Strength Concrete", Journal of Structural Fire Engineering, Vol. 1, No 1, pp. 17-27, 2010.

[18] P. Kalifa, G. Chene, and Ch. Galle, "Hightemperature behaviour of HPC with polypropylene fibers from spalling to microstructure”, Cement and Concrete Research, Vol. 31, pp. 1487-1499, 2001.
[19] Jianzhuang Xiao and H. Falkner, "On residual strength of high-performance concrete with and without polypropylene fibers at elevated temperatures, Fire Safety Journal, Vol. 41, pp. 115-121, 2006.

[20] Y.N. Chana, X. Luo and W. Sun, "Compressive strength and pore structure of high-performance concrete after exposure to high temperature up to $800{ }^{\circ} \mathrm{C}$ ”, Cement and Concrete Research, Vol. 30, pp. 247-251, 2000

[21] C.S. Poon, Z.H. Shui and L. Lam, “Compressive behavior of fiber reinforced high-performance concrete subjected to elevated temperatures”, Cement and Concrete Research, Vol. 34, pp. 2215-2222, 2004.

[22] Jianxin Ma and Jorg Dietz, "Ultra High Performance Self Compacting Concrete", Institute for structural concrete, University Leipzig, LACER No. 7, pp.33-43, 2002.

[23] Jianxin Ma and Marko Orgass, "Comparative Investigations on Ultra-High Performance Concrete with and without Coarse Aggregates”, Institute for structural concrete, University Leipzig, LACER No. 9,pp.1-10, 2004. 